\title{
The Role of Bradykinin System in Type 2 Diabetes
}

Jagdish N Sharma*

Department of Pharmacology and Therapeutics, Faculty of Pharmacy, Health Sciences Centre, Kuwait University, PO Box 24923, Safat, Kuwait

\section{The Bradykinin System}

The kinins are pharmacologically active polypeptides, which are released in the tissues and body fluids as a result if the enzymatic action of kallikreins on kininogens. The kinin family includes BK (Arg-ProPro-gly-Phe-Ser-Pro-Phe-Arg), kallidin (Lys- -Arg-Pro-Pro-Gly-PheSer-Pro-Phe-Arg) and methionyl-lysyl-BK (Met-Lys-Arg-Pro-ProGly-Phe-Arg). Kallidin and methionyl-lysyl-BK are converted into BK by aminopeptidases present in plasma and urine [1]. Kinins are rapidly $(<15 \mathrm{sec})$ inactivated by circulating kininases [2].

Kininogens are multifunctional proteins derived mainly from alpha -2 globulin. In humans, the two forms of kininogens are; High Molecular Weight Kininogen (HMWK) and Low Molecular Weight Kininogen (LMWK) [3].

These kininogens vary from each others in molecular weight, susceptibility to plasma and tissue kallikreins and in their physiological properties [4]. They are synthesized in the liver and circulate in the plasma and other body fluids. In addition, there is a T-kininogen in the rat plasma, which is considered to be an acute phase reactant of inflammation [5]. This kininogen releases T-kinin by the enzymatic action of T- kallikrein in rats [6]. Tissue kallikrein is found in various organs such as the kidney, heart and synovial tissue $[7,8]$. These kallikreins differ from one another in molecular weight, biological function, physicochemical and immunological properties [9]. The tissue kallikrein is synthesized in the cells as a precursor and converted into active form by the cleavage of an amino terminal peptide [10]. Active tissue kallikrein acts on LMWK to release kallidin. The plasma kallikrein is found in circulation in an inactive form, which is known as prekallikrein or Fletcher factor [11]. This inactive prekallikrein is converted to active kallikrein by activated hageman factor (XIIa). In addition, plasma kallikrein is able to convert inactive factor XII to XIIa by positive feedback reaction. The plasma prekallikrein and HMWK are present together in a complex form [12]. Factor XIIa and factor XI circulate with HMWK in bound form [13]. In this way, factor XI can be converted into XIa for the participation in the intrinsic coagulation cascade [14]. In immunological reactions, the tissue proteoglycone and mast cell heparin might act as an initiating surface for initial activation of the Hageman factor [15]. It seems that the kinins may be generated in parallel with the formation of thrombin at inflammatory sites, since inactive plasma kallikrein can be activated by coagulant Hageman factor. The tissue kallikrein multigene family comprises a closely related cluster of genes that vary in number between the different mammalian species: 24 genes have been identified in the mouse, 20 in the rat, 3 in humans and 3 in the hamster [9].

Several Restriction Fragment Length Polymorphisms (RFLP) has been mapped in tissue kallikrein gene and their regulatory regions in Spontaneously Hypertensive Rats (SHR) [16]. These findings may reflect a possible difference in the tissue kallikrein gene locus between SHR and normotensive Wistar-Kyoto Rats (WKYR). A tissue kallikrein RFLP has been indicated to cosegregate with high BP in the F2 offspring of SHR and normotensive Brown Norway rats crosses [17]. This finding strongly suggests a possibility of SHR. The kininases, kinin inactivating enzymes, are present in the plasma, endothelial cells and in the tissues to regulate the physiological functions of the kinins in the body. These are known as kininase I, Kininase II or angiotensin converting enzyme (ACE) and enkaphalinase. In plasma, kininase I cleaves the C-terminal arginine of BK to form des-Arg9-BK [18]. Kininase II causes inactivation of BK by releasing pentapeptide (ArgPro-Pro-Gly-Phe0 and tripeptide (Ser-Pro-Phe) fragments (Figure 1).

\section{The Bradykinin System and Diabetes}

Diabetes has been implicated as a major risk factor in the development of cardiovascular and renal complications. Previous studies have indicated altered activities of the bradykinin-forming components [19] in diabetic patients and experimental animals. High prevalence rates (25\%) of diabetes have been documented in Kuwaiti population [20]. Type 2 diabetes can lead to hypertension, renal and cardiac complications resulting in high rates of mortality worldwide and in Kuwait as well. Bradykinin (BK), a pharmacologically active polypeptide, is one of kinins which is released in the tissues and body fluids as a result of enzymatic action of kallikreins on kininogens. The two types of kallikrein are tissue kallikrein and plasma kallikrein. Plasma kallikrein is also present in inactive form known as prekallikrein, which can be activated into kallikrein. Tissue kallikrein is mainly expressed in the kidney (urine), glandular tissue, vasculature, [21] heart and brain. It preferentially acts on low molecular weight kininogen substrate to release lysyl-BK. Tissue kallikrein has also been reported to be present in plasma [22,23] Plasma kallikrein preferentially acts on high molecular weight kininogen substrate to release BK. BK promotes both cardiovascular and renal functions, for example, vasodilation, naturesis and diuresis $[24,25] \mathrm{BK}$ is rapidly $(<15 \mathrm{sec})$ inactivated by circulating kinases [26] BK acts on B1receptor (B1R) and B2 receptor (B2R) [27] to elicit physiological and pharmacological actions. It has been shown previously that type 1 diabetic patients are at a risk of developing nephropathy, having increased renal tissue kallikrein and BK levels [28]. In addition, raised plasma prekallikrein levels in type 1 diabetes has been considered as a risk marker for hypertension and nephropathy [29] It has been shown that diabetic rats with moderate hyperglycemia, in association with increased urinary kallikrein excretion, resulted in reduced renal vascular resistance (RVR) and increased both renal plasma flow (RPF) and glomerular filtration rate (GFR) [28,29].

The contribution of the renal BK-forming components has been implicated in the renal injury [30] in experimental and type 1 diabetes.

*Corresponding author: Jagdish N Sharma, Department of Pharmacology and Therapeutics, Faculty of Pharmacy, Health Sciences Centre, Kuwait University, PO Box 24923, Safat, Kuwait, Tel: ++965-2463-6530; Fax: +965-2534-2807; E-mail: j.n.sharma@hsc.edu.kw

Received February 15, 2016; Accepted March 15, 2016; Published March 23 2016

Citation: Sharma JN (2016) The Role of Bradykinin System in Type 2 Diabetes. J Diabetes Metab 7: 658. doi:10.4172/2155-6156.1000658

Copyright: () 2016 Sharma JN. This is an open-access article distributed under the terms of the Creative Commons Attribution License, which permits unrestricted use, distribution, and reproduction in any medium, provided the original author and source are credited. 


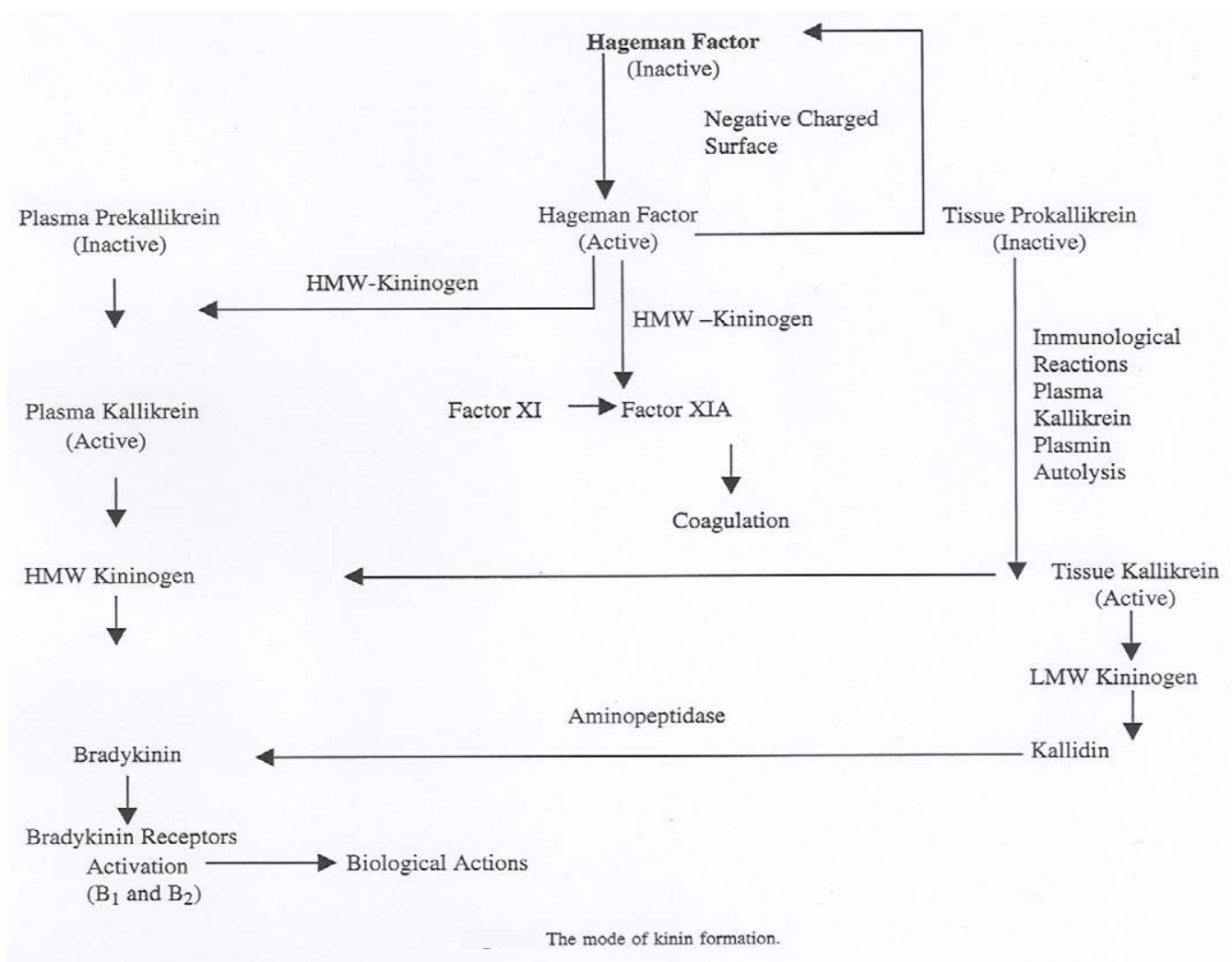

Figure 1: Shows the bradykinin formation, activation and inhibition pathways.

The urinary and plasma BK-forming components are comprised of proteins that mediate their effects on vasculature by releasing BK [3033]. It is also known that the tissue kallikrein present in the urine is originating from the kidney and it reflects the renal activity of BK [9]. Higher concentrations of prekallikrein levels may suggest the onset of renal abnormalities. In fact, high plasma prekallikrein levels have been documented in type 1 diabetic patients [27]. These investigators suggested that increased plasma prekallikrein level could be a risk factor for hypertension and nephropathy in type 1 diabetes. The present study may also suggest a similar mechanism for developing hypertension and nephropathy in type 2 diabetic patients. Therefore, plasma prekallikrein could be a useful tool for monitoring diabetic patients for developing hypertension and/or renal abnormalities.

It is of interest to suggest that the early detection of type 2 diabetes based on high urinary kallikrein would be an indicator for future renal abnormality that can be prevented with the treatment. In addition, high plasma prekallikrein activity may serve as an indicator for causing hypertension and left ventricular hypertrophy in diabetic rats [34].

On the other hand, we observed reduced levels of total urinary kininogen in type 2 diabetic patients. This observation might be a reflection on the utilization of kininogen to form $B K$, a proinflammatory agent as previously reported $[35,36]$. BK1R and BK2R antagonists may normalize the diabetic state in experimentally induced diabetes in mice [37]. Thus, BK antagonist may be targeted for use in diabetic disorders. Moreover, high levels of tissue kallikrein could diminish glucose transport to the tissue [22]. This may also suggest that high levels of tissue kallikrein in diabetic patients might be a predisposing factor in the induction of type 2 diabetes due to the inhibition of glucose transfer to the tissues [38]. Plasma levels of tissue kallikrein have been reported to be increased in type 2 diabetes as previously reported $[39,40]$. In the present study however, we also observed high concentrations of plasma tissue kallikrein, which presumably be due to the hyperactivity of the BK-forming system to induce systemic metabolic abnormalities. It has been reported that tissue kallikrein activates B2R directly without BK generation [41]. Furthermore, diabetic rats have been shown to have the glomerular B1R and B2R expression in the diabetic state [42]. Thus, BK system has significant role in the genesis of type 2 diabetes and agents that participates in the BK pathways regulation may be valuable in the development of diabetes.

\section{References}

1. Nolly HL, Brotis $\mathrm{J}$ (1981) Kinin- forming enzyme in rat cardiac tissue. Am J Physiol 265: H1209-H1214.

2. Sharma JN, Kesavarao U (1996) Cardiac kallikrein in hypertensive and normotensive rats with and without diabetes. Immunopharmacology 33: 341343.

3. Sharma JN, Uma K, Yusof APM (1998): Left ventricular hypertrophy and its relation to the cardiac kinin- forming system in hypertensive and diabetic rats. Int J Cardiol 63: 229- 235.

4. Sharma JN, Kesavarao U, Yusof AP (1999) Altered cardiac tissue and plasma kininogen levels in hypertensive and diabetic rats. Immunopharmacology 43: 129-132.

5. Oza NB, Goud HD (1992) Kininogenase of the aortic wall in spontaneously hypertensive rats. J Cardiovasc Pharmacol 20 Suppl 9: S1-S3.

6. Nolly H, Carretero OA, Scicli AG (1993) Kallikrein release by vascular tissue. Am J Physiol 265: H1209-H1214.

7. Vegh A, Szekeres L, Parratt JR (1991) Local intracoronary infusions of bradykinin profoundly reduce the severity of ischaemia-induced arrhythmia in anaesthetized dogs, Br J Pharmacol 104: 294- 295.

8. Linz W, Wiemer G, Schölkens BA (1993) Bradykinin prevents left ventricular hypertrophy in rats. J Hypertens Suppl 11: S96-S97. 
9. Vegh A, Papp JG, Parratt J (1994) Attenuation of the antiarrhythmic effects of ischaemic preconditioning by blockade of bradykinin $\mathrm{B} 2$ receptors. $\mathrm{Br} J$ Pharmacol 113: 1167-1172.

10. Wall TM, Sheehy R, Hartman JC (1994) Role of bradykinin in myocardial preconditioning. J Pharmacol Exp Ther 270: 681-689.

11. Linz W, Wiemer G, Schölkens BA (1993) Contribution of bradykinin to the cardiovascular effects of ramipril. J Cardiovasc Pharmacol 22 Suppl 9: S1-8.

12. Sharma JN (1984) Kinin-forming system in the genesis of hypertension. Agents Actions 14: 200-205

13. Sharma JN (1988) Interrelationship between the kallikrein-kinin system and hypertension: a review. Gen Pharmacol 19: 177-187.

14. Sharma JN (1989) Contribution of kinin system to the antihypertensive action of angiotensin converting enzyme inhibitors. Adv Exp Med Biol 247A: 197-205.

15. Sharma JN, Uma K, Noor AR (1996) Blood pressure regulation by the kallikreinkinin system. Gen Pharmacol 27: 55- 63.

16. Sharma JN (1990) Does kinin mediate the hypotensive action of angiotensin converting enzyme (ACE) inhibitors? Gen Pharmacol 21: 451-457.

17. Sharma JN (1992) Involvement of the kinin- forming system in physiopathology of rheumatoid inflammation. Agents Actions 38: 343- 361.

18. Nagayasa T, Nagasawa S (1979) Studies of human kininogen. Isolation, characterization, and cleavage by plasma kallikrein of high molecular weight (HMW) kininogen. J Biochem 85: 249- 258.

19. Muller-Esterl W, Iwanaga S and Nakanishi S (1986): Kininogens revisited. TIBS 11: 336- 339.

20. Greenbaum LM (1984) T-kinin and T-kininogen-children of new technology. Biochem Pharmacol 33: 2943-2944

21. Okamoto H, Greenbaum LM (1983) Pharmacological properties of T-kinin (isoleucyl-seryl-bradykinin) from rat plasma. Biochem Pharmacol 32: 26372638.

22. Nustad K, Vaaje K, Pierce JV (1975) Synthesis of kallikreins by rat kidney slices. Br J Pharmacol 53: 229-234.

23. Sharma JN, Zeitlin IJ, Deodhar SD, Buchanan WW (1983): Detection of tissue kallikrein- like activity in inflamed synovial tissue. Arch Int Pharmacody Ther 262: 279- 286

24. Bhoola KD, Figueroa CD, Worthy K (1992) Bioregulation of kinins: kallikreins, kininogens, and kininases. Pharmacol Rev 44: 1-80.

25. Takada Y, Skidgel RA, Erdös EG (1985) Purification of human urinary prokallikrein. Identification of the site of activation by the metalloproteinase thermolysin. Biochem J 232: 851-858.

26. Weiss AS, Gallin JL, Kaplan AP (1974) Fletcher factor deficiency: a diminished rate of Hageman factor activation caused by absence of prekallikrein with abnormalities of coagulation, fibrinolysis, chemotactic activity and kinin generation. J Clin Invest 53: 622- 633
27. Cochrane CG, Revak SD, Wuepper KD (1973) Activation of Hageman factor in solid and fluid phases. A critical role of kallikrein. J Exp Med 138: 1564-1583.

28. Griffin JH, Cochrane CG (1976) Mechanisms for the involvement of high molecular weight kininogen in surface-dependent reactions of Hageman factor. Proc Natl Acad Sci U S A 73: 2554-2558.

29. Mandle RJ, Colman RW, Kaplan AP (1976) Identification of prekallikrein and high-molecular-weight kininogen as a complex in human plasma. Proc Nat Acad Sci U S A 73: 4179-4183.

30. Thompson RE, Mandle R Jr, Kaplan AP (1977) Association of factor XI and high molecular weight kininogen in human plasma. J Clin Invest 60: 13761380.

31. Leeb-Lundberg LMF, Marceau F, Muller-Esterl W, (2005) Classification of the kinin receptor family: From Molecular mechanisms to Pathophysiological consequences. International Union of Pharmacology. XLV. Pharmacol 57: 27 77.

32. Abdella N, Al Arouj M, Al Nakhi A, Al Assoussi A, Moussa M (1998) Non-insulindependent diabetes in Kuwait: prevalence rates and associated risk factors. Diabetes Res Clin Pract 42: 187-196.

33. Al-Shoumer KA, Al-Asousi AA, Doi SA, Vasanthy BA (2008) Serum leptin and its relationship with metabolic variables in Arabs with type 2 diabetes mellitus. Ann Saudi Med 28: 367-370.

34. Sharma JN (2006) The tissue kallikrein-kininogen-kinin pathways: role in cardiovascular system. Arch Med Res 37: 299-306.

35. Rabito SF, Scicli AG, Kher V, Carretero OA (1982) Immunoreactive glandular kallikrein in rat plasma: a radioimmunoassay for its determination. Am J Physiol 242: H602-610.

36. Yayama K, Kunimatsu N, Teranishi Y, Takano M, Okamoto H (2003) Tissue kallikrein is synthesized and secreted by human vascular endothelial cells. Biochim Biophys Acta 1593: 231-238.

37. Katori M, Majima M (2006) A missing link between a high salt intake and blood pressure increase. J Pharmacol Sci 100: 370-390.

38. Sharma JN, Uma K, Yusof AP (1998) Left ventricular hypertrophy and its relation to the cardiac kinin-forming system in hypertensive and diabetic rats. Int J Cardiol 63: 229-235.

39. Sharma JN, Uma K, Noor AR, Rahman AR (1996) Blood pressure regulation by the kallikrein-kinin system. Gen Pharmacol 27: 55-63.

40. Jaffa AA, Durazo-Arvizu R, Zheng D, Lackland DT, Srikanth S, et al. (2003) Plasma prekallikrein: a risk marker for hypertension and nephropathy in type diabetes. Diabetes 52: 1215-1221.

41. Harvey JN, Jaffa AA, Margolius HS, Mayfield RK (1990) Renal kallikrein and hemodynamic abnormalities of diabetic kidney. Diabetes 39: 299-304.

42. Jaffa AA, Rust PF, Mayfield RK, (1995) Kinin, a mediator of diabetes induced glomerular hyper filtration. Diabetes 44: 156-160 